\title{
LA INFLUENCIA DEL AUTOCONCEPTO EN EL RENDIMIENTO ACADÉMICO: UNA REVISIÓN TEÒRICA
}

Bella del Rocío Aguilar Prieto, Ana María Navarro Domínguez, Rocío Rodríguez Jara, Virginia de la Cinta Trillo Fernández. Universidad de Huelva

\section{RESUMEN}

Existen investigaciones que confirman la relación existente entre el autoconcepto y la autoestima con respecto al rendimiento académico. En este sentido, el objetivo principal de este estudio se centra en revisar y exponer el nivel de influencia de ambos constructos con el rendimiento académico, en estudiantes que se encuentran en proceso de formación. Para ello, primeramente, se definirán los conceptos claves para posteriormente proceder a describir diferentes estudios sobre esta temática. En segundo lugar, se plasmarán diversos programas sobre intervención en autoconcepto y autoestima con la finalidad de conocer, informar y aplicar dichos programas en los centros educativos y familia entre otros.

Palabras clave: autoconcepto, autoestima, rendimiento académico, programas de intervención educativa.

\section{INTRODUCCIÓN}

El autoconcepto y la autoestima son términos íntimamente ligados. De hecho, existen diversos autores que tienden a utilizar estos términos de forma indistinta, mientras que otros limitan el término autoconcepto a los aspectos cognitivos del "sí mismo" y utilizan la autoestima para los aspectos evaluativos-afectivos. No obstante, en líneas generales, se acepta que el autoconcepto engloba ambos aspectos.

Según Saura (1995), el autoconcepto hace referencia al "conjunto de imágenes, sentimientos y rasgos que la persona reconoce como parte de sí misma" (p.20).

Por otro lado, según Duclos (2011), el origen de la autoestima se sitúa en los primeros años de vida a partir de los mensajes e imágenes que los padres devuelven al niño con los que él forma su primer concepto de sí mismo, ya que sus padres son sus principales referentes. El niño se ve influido por esos mensajes y las personas de su entorno proyectan en él una imagen determinada a través de sus opiniones, actos y afectos en las interacciones que se establecen. De modo que las bases de la autoestima se conforman en los primeros años de vida ya que si un niño se siente aceptado por su familia le permite desarrollar sentimientos de aceptación, aprecio, valor personal y seguridad que constituye la base para un buen nivel de autoestima para el futuro.

Finalmente, en la actualidad, el rendimiento académico ha sido estudiado mediante un enfoque multidimensional, ya que se interrelaciona con múltiples variables, siendo los factores que influyen en él los socioeconómicos, la amplitud de los programas de estudio, las metodologías de enseñanza utilizadas, la dificultad de emplear una enseñanza personalizada, los conceptos previos que tienen los alumnos, así como el nivel de pensamiento formal de los mismos (Benítez, Giménez y Osicka, 2000). En definitiva, el rendimiento es definido como "la productividad del sujeto, el producto 
final de la aplicación de su esfuerzo, matizado por sus actividades, rasgos y la percepción más o menos correcta de los cometidos asignados" (Forteza, 1975, p.72).

\section{INVESTIGACIONES}

\section{En la siguiente tabla se muestra las investigaciones que se han llevado a cabo en los últimos años sobre la temática:}

\begin{tabular}{|c|c|c|c|c|}
\hline INVESTIGACIONES & OBJETIVO & MUESTRA & PRUEBAS & CONCLUSIONES \\
\hline $\begin{array}{l}\text { Autoconcepto académico y } \\
\text { rendimiento académico de los } \\
\text { estudiantes de Lengua y } \\
\text { Literatura de la Universidad } \\
\text { Nacional Pedro Ruíz Gallo, del } \\
\text { ciclo académico 2009-II. } \\
\text { (Alvarez Gonzaga, B. R., } \\
\text { 2009). }\end{array}$ & $\begin{array}{l}\text { Determinar el nivel de } \\
\text { autoconcepto académico de } \\
\text { los estudiantes; determinar si } \\
\text { existe una dependencia entre } \\
\text { el nivel de autoconcepto y el } \\
\text { rendimiento académico; } \\
\text { determinar si existe una } \\
\text { diferencia significativa entre el } \\
\text { autoconcepto académico de } \\
\text { los alumno/as; y, determinar } \\
\text { cuáles son los indicadores que } \\
\text { se encuentran a } \\
1 \text { desviación estándar con } \\
\text { respecto al promedio general } \\
\text { de los indicadores. }\end{array}$ & 26 sujetos & $\begin{array}{l}\text { Test } \\
\text { estandarizado de } \\
20 \text { ítems con } \\
\text { escala Likert de } 1 \\
\text { a } 5 \text { siendo } 1 \text { la } \\
\text { menos frecuencia } \\
\text { (nunca) y } 5 \text { la } \\
\text { mayor frecuencia } \\
\text { (siempre). }\end{array}$ & $\begin{array}{l}\text { No existen diferencias } \\
\text { significativas entre el } \\
\text { autoconcepto académico de } \\
\text { los alumno/as; se determinó } \\
\text { que no existe una } \\
\text { dependencia entre la } \\
\text { variable autoconcepto } \\
\text { académico y rendimiento } \\
\text { académico en los } \\
\text { estudiantes; y, se determinó } \\
\text { que el incremento del } \\
\text { rendimiento académico de } \\
\text { los estudiantes se deben a } \\
\text { un } 2 \% \text { al autoconcepto. }\end{array}$ \\
\hline $\begin{array}{l}\text { La influencia del autoconcepto } \\
\text { en el rendimiento académico } \\
\text { en estudiantes universitarios } \\
\text { (Gallardo López, B., Garfella } \\
\text { Esteban, P. R., Sánchez Peris, } \\
\text { F. y, Serra Carbonell, B. } \\
\text { 2009). }\end{array}$ & $\begin{array}{l}\text { Conocer si existe relación } \\
\text { entre los diversos tipos o } \\
\text { dimensiones del autoconcepto } \\
\text { y el rendimiento y si el } \\
\text { autoconcepto tiene o no valor } \\
\text { predictivo sobre dicho } \\
\text { rendimiento. }\end{array}$ & $\begin{array}{l}1298 \\
\text { sujetos }\end{array}$ & $\begin{array}{l}\text { Cuestionario } \\
\text { AF5. }\end{array}$ & $\begin{array}{l}\text { Los resultados de esta } \\
\text { investigación corroboraron } \\
\text { la relevancia del } \\
\text { autoconcepto sobre el } \\
\text { rendimiento académico. }\end{array}$ \\
\hline $\begin{array}{l}\text { El autoconcepto social y el } \\
\text { rendimiento académico en la } \\
\text { educación artística escolar del } \\
\text { alumnado preadolescente } \\
\text { (Lekue, P., 2010). }\end{array}$ & $\begin{array}{l}\text { Conocer si existe relación } \\
\text { entre el rendimiento } \\
\text { académico de los escolares } \\
\text { adolescentes y el } \\
\text { autoconcepto social. }\end{array}$ & $\begin{array}{l}606 \\
\text { sujetos. }\end{array}$ & $\begin{array}{l}\text { Cuestionario de } \\
\text { autoconcepto } \\
\text { social. }\end{array}$ & $\begin{array}{l}\text { Existen diferencias } \\
\text { significativas entre el } \\
\text { autoconcepto social y el } \\
\text { rendimiento académico. } \\
\text { También hay diferencias } \\
\text { negativas entre } \\
\text { autoconcepto y edad. }\end{array}$ \\
\hline $\begin{array}{l}\text { Diferencias de género en el } \\
\text { autoconcepto general y } \\
\text { académico de estudiantes de } \\
4^{\circ} \text { de ESO (Padilla Carmona, } \\
\text { M. T., García Gómez, S. y, } \\
\text { Suárez Ortega, M. 2010). }\end{array}$ & $\begin{array}{l}\text { Identificar si existen } \\
\text { diferencias de género entre } \\
\text { autoconcepto, rendimiento } \\
\text { académico y otras variables, } \\
\text { partiendo de la base de la } \\
\text { relación existente entre dichas } \\
\text { variables. }\end{array}$ & $\begin{array}{l}415 \\
\text { sujetos. }\end{array}$ & $\begin{array}{l}\text { Inventario A-1: } \\
\text { Exploración de la } \\
\text { autoimagen de } \\
\text { chicas y chicos; } \\
\text { compuesto por } \\
16 \text { ítems, a su } \\
\text { vez, agrupados } \\
\text { en } 4 \text { subescalas. }\end{array}$ & $\begin{array}{l}\text { No se encontraron } \\
\text { diferencias significativas } \\
\text { entre el autoconcepto y el } \\
\text { rendimiento académico } \\
\text { entre ambos sexos. }\end{array}$ \\
\hline $\begin{array}{l}\text { Relación entre autoeficacia, } \\
\text { autoestima, asertividad y } \\
\text { rendimiento académico, en } \\
\text { estudiantes que ingresaron a } \\
\text { terapia ocupacional, (Aluicio } \\
\text { G., A. y Revellino, M., 2010). }\end{array}$ & $\begin{array}{l}\text { Describir si existe relación } \\
\text { entre la autoestima, la } \\
\text { autoeficacia, la asertividad y el } \\
\text { rendimiento académico. }\end{array}$ & 43 sujetos. & $\begin{array}{l}\text { Inventario de } \\
\text { autoestima de } \\
\text { Coopersmith // } \\
\text { Escala de } \\
\text { asertividad de } \\
\text { Rathus // Escala } \\
\text { de autoeficacia } \\
\text { generalizada // } \\
\text { Promedio de } \\
\text { calificaciones del } \\
2010 \\
\text { (rendimiento } \\
\text { académico) }\end{array}$ & $\begin{array}{l}\text { Se rechazaron las hipótesis } \\
\text { de que a mayor autoestima, } \\
\text { mayor autoeficacia y mayor } \\
\text { asertividad } \rightarrow \text { mayor } \\
\text { rendimiento académico. }\end{array}$ \\
\hline
\end{tabular}




\section{PROGRAMAS DE INTERVENCIÓN}

Los programas de intervención en autoconcepto y autoestima se basan en un conjunto de acciones sistematizadas, planificadas y basadas en necesidades identificadas, en este caso la mejora de ambos constructos. Una de las principales limitaciones de estos programas es que, con frecuencia, no se encuentran apoyados en la investigación empírica y no se muestran evidencias acerca de cuáles son los factores que explican los resultados. (Rodríguez y Caño, 2012).

\section{A continuación, se realizará una síntesis de varios programas de intervención:}

\begin{tabular}{|c|c|c|}
\hline NOMBRE DEL PROGRAMA & ESTRATEGIAS DE INTERVENCIÓN & RESULTADOS \\
\hline $\begin{array}{l}\text { Mejora de la autoestima en el } \\
\text { aula (Mestre y Frías, 1996). }\end{array}$ & $\begin{array}{l}\text { 1. Evaluación de situaciones problemáticas en el } \\
\text { ámbito escolar. } \\
\text { 2. Reducción ansiedad ante situaciones } \\
\text { estresantes mediante técnicas de relajación y } \\
\text { autocontrol. } \\
\text { 3. Desarrollo de técnicas de solución de problemas } \\
\text { para mejorar la adaptación al entorno. } \\
\text { 4. Estrategias de aprendizaje afectivo- } \\
\text { emocionales. } \\
\text { 5. Cambio de actitudes ante situaciones } \\
\text { estresantes. }\end{array}$ & $\begin{array}{l}\text { Efectos significativos sobre autoestima, } \\
\text { efectos de factores principales y la } \\
\text { interacción. }\end{array}$ \\
\hline $\begin{array}{l}\text { Prevención de emociones } \\
\text { negativas (Olmedo, 1997). }\end{array}$ & $\begin{array}{l}\text { 1. Incremento de la autoestima mediante auto- } \\
\text { observación y reestructuración cognitiva. } \\
\text { 2. Enseñanza de habilidades de relajación físicas } \\
\text { (relajación progresiva o entrenamiento } \\
\text { autógeno) y mentales (basadas en } \\
\text { imaginación). } \\
\text { 3. Aprendizaje de habilidades sociales con énfasis } \\
\text { 4. Enducta asertiva. }\end{array}$ & $\begin{array}{l}\text { Se encuentran efectos significativos en la } \\
\text { medida de autoestima. }\end{array}$ \\
\hline $\begin{array}{l}\text { Galatea (Cava y Musito, } \\
\text { 1999). }\end{array}$ & $\begin{array}{l}\text { 1. Desarrollar un ambiente de confianza y apoyo } \\
\text { en el aula. } \\
\text { 2. Centrarse en los aspectos positivos que } \\
\text { potencialmente todos los alumnos tienen. } \\
\text { 1. 3.Profundizar en un mayor autoconocimiento } \\
\text { 2. 4.Reflexionar acerca de sus metas y } \\
\text { aspiraciones } \\
\text { 3. 5.Analizar los impedimentos que dificultan } \\
\text { 4. alcanzar los objetivos } \\
\text { 5. } \\
\text { 6.Potenciar relaciones con iguales y amistad } \\
\text { Potenciar relaciones de alumnos con sus } \\
\text { respectivas familias. }\end{array}$ & $\begin{array}{l}\text { El programa parece útil tanto para } \\
\text { aquellos niños con dificultades } \\
\text { socioafectivas, como para los niños bien } \\
\text { adaptados socialmente, lo cual lo } \\
\text { convierte en un programa con una } \\
\text { finalidad, terapéutico y preventivo. }\end{array}$ \\
\hline $\begin{array}{l}\text { Entrenamiento en autoestima } \\
\text { y habilidades cognitivas } \\
\text { (Barrett, Webster y Wallis, } \\
\text { 1999). }\end{array}$ & $\begin{array}{l}\text { 1. Entrenamiento en habilidades para generar un } \\
\text { estilo más positivo de pensamiento, } \\
\text { comunicación, percepción y solución de } \\
\text { problemas. } \\
\text { 2. Moldeamiento y refuerzo de nuevas habilidades } \\
\text { y mejorar las existentes. } \\
\text { 3. Uso de tareas para casa semanales para } \\
\text { reforzar habilidades desarrolladas en grupo e } \\
\text { incrementar generalización. }\end{array}$ & $\begin{array}{l}\text { Se encuentra un efecto principal de la fase } \\
\text { y una interacción del tratamiento por la } \\
\text { fase. Análisis más detallados mostraron } \\
\text { que los efectos de fase fueron sólo } \\
\text { significativos en el grupo de intervención, } \\
\text { y que en la segunda fase, el grupo de } \\
\text { intervención mostró mejores resultados en } \\
\text { autoestima que ambos grupos de control. }\end{array}$ \\
\hline
\end{tabular}




\begin{tabular}{|c|c|c|c|}
\hline $\begin{array}{l}\text { Intervención en conducta } \\
\text { social, relaciones intragrupo, } \\
\text { autoconcepto y cogniciones } \\
\text { prejuiciosas (Garaigordobil, } \\
2000 \text { ). }\end{array}$ & & $\begin{array}{l}\text { Mejora del autoconcepto. } \\
\text { Incremento de la comunicación intragrupo, } \\
\text { aceptación iguales e interacciones amistosas. } \\
\text { Desarrollo de conductas sociales positivas } \\
\text { (prosociales, liderazgo y autocontrol, etc.) y } \\
\text { reducción de conductas sociales negativas. } \\
\text { Identificación de percepciones y prejuicios y } \\
\text { análisis discriminativos. } \\
\text { Aprendizaje de técnicas para análisis y solución } \\
\text { de conflictos. }\end{array}$ & $\begin{array}{l}\text { MANOVA sobre conjunto de medidas de } \\
\text { autoconcepto mostró diferencias entre } \\
\text { grupos tratamiento y control en la fase } \\
\text { post y diferencia en las puntuaciones entre } \\
\text { fase post y pretratamiento. ANOVAS } \\
\text { sobre medidas autoconcepto mostraron } \\
\text { diferencias significativas para } \\
\text { autoconcepto social y tendencia a } \\
\text { significación para académico. Los } \\
\text { participantes con puntuaciones bajas en } \\
\text { autoconcepto social mostraron mayor } \\
\text { cambio que participantes con } \\
\text { puntuaciones medias y altas. }\end{array}$ \\
\hline
\end{tabular}

\section{CONCLUSIÓN}

Esta revisión analiza la relación entre el autoconcepto y la autoestima con respecto al rendimiento académico. Teniendo en cuenta los resultados obtenidos en las investigaciones analizadas se concluye que sí existe relación (Gallardo López, B., Garfella Esteban, P. R., Sánchez Peris, F. y, Serra Carbonell, B. (2009); Lekue, P., (2010); Padilla Carmona, M. T., García Gómez, S. y, Suárez Ortega, M. (2010))

No obstante, algunos resultados obtenidos en las investigaciones revisadas no son estadísticamente significativos (Aluicio G., A. y Revellino, M., (2010); Álvarez Gonzaga, B. R., (2009)). Esto puede ser debido a que la muestra no es representativa a la población, ya que los sujetos que han conformado dicha muestra son muy pocos en comparación con el número de sujetos de los estudios que sí resultaron estadísticamente significativos. Por ello, se concluye, que se ha podido generar sesgos muestrales.

Por otro lado, la relación entre autoconcepto y autoestima con el rendimiento académico no es estadísticamente significativa con respectos al sexo; asimismo, si existen diferencias entre estas variables y la edad (Padilla Carmona, M. T., García Gómez, S. y, Suárez Ortega, M. (2010)).

Con respecto a los programas de intervención dirigidos a mejorar el autoconcepto y la autoestima y, por ende, mejorar el rendimiento académico, se ha comprobado que las personas que participaron en la intervención han tenido una evolución favorable con respecto a los constructos trabajados en dichos programas, por lo cual, se puede concluir que han sido efectivos (Barrett, Webster y Wallis, (1999); Cava y Musito, (1999); Garaigordobil, (2000); Mestre y Frías, (1996); Olmedo, (1997)).

Para finalizar, se podría concluir que el alto rendimiento académico podría estar íntimamente relacionado con niveles elevados de autoestima y autoconcepto.

\section{BIBLIOGRAFÍA}

Aluicio G., A. y Revellino, M. (2010). Relación entre autoeficacia, autoestima, asertividad y rendimiento académico, en estudiantes que ingresaron a terapia ocupacional, el año 2010. 
Alvarez Gonzaga, B. R. (2009). Autoconcepto académico y rendimiento académico de los estudiantes de Lengua y Literatura de la Universidad Nacional Pedro Ruíz Gallo, del ciclo académico 2009-II. Estudiante de Lengua y Literatura de la Facultad de Ciencias Histórico Sociales y Educación de la Universidad Nacional Pedro Ruíz Gallo.

Benítez, M; Gimenez, M. y Osicka, R. (2000). Las asignaturas pendientes y el rendimiento académico: ¿existe alguna relación?. Universidad Nacional del Nordeste Comandante Fernandez. Argentina

Barrett PM, Webster HM y Wallis JR (1999). Adolescent self-esteem and cognitive skills training: A school-based intervention. Journal of Child and Family Studies, 8, 217227.

Cava, M. J.; Musitu, G. (1999). Evaluación de un programa de intervención para la potenciación de la autoestima. Intervención Psicosocial, 1999, Vol. 8, n³, 369- 383

Duclos, G. (2011). La autoestima, un pasaporte para la vida. Madrid: Edaf

Forteza, J. (1975). Modelo Instrumental de las Relaciones entre Variables Motivacionales y Rendimiento. Revista de Psicología Aplicada, 132, 75-91.

Gallardo López, B., Garfella Esteban, P. R., Sánchez Peris, F. y, Serra Carbonell, B. (2009). La influencia del autoconcepto en el rendimiento académico en estudiantes universitarios. REOP, Vol. 20, $\mathrm{N}^{\circ} 1,1^{\circ}$ Trimestre, pp. 16-28.

Garaigordobil M (2000). Intervención psicológica en adolescentes: un programa para el desarrollo de la personalidad y la educación en derechos humanos. Madrid: Pirámide.

Lekue, P. (2010). El autoconcepto social y el rendimiento académico en la educación artística escolar del alumnado preadolescente. Jornada de Psicodidáctica. Departamento de Didáctica de la expresión Musical, Plástica y Corporal: Euskal Herriko Unibertsitate.

Mestre V y Frías D (1996). La mejora de la autoestima en el aula. Aplicación de un programa para niños en edad escolar (11-14 años). Revista de Psicología General y Aplicada, 49, 279-290.

Olmedo M (1997). Aplicación y evaluación de un programa de afrontamiento de problemas emocionales en adolescentes. Servicio de Publicaciones Universidad de Jaén. Micropublicaciones ETD.

Padilla Carmona, M. T., García Gómez, S. y, Suárez Ortega, M. (2010). Diferencias de género en el autoconcepto general y académico de estudiantes de $4^{\circ}$ de ESO. Revista de Educación, 352. Mayo-Agosto, 2010, pp. 495-515.

Rodriguez, C.; Caño, A. (2012). Autoestima en la adolescencia: análisis y estrategias de intervención. International Journal of Psychology and Psychological Therapy, 12, $3,389-403$

Saura Calixto, P. (1995). La educación del autoconcepto: cuestiones y propuestas. Servicios de publicaciones, Universidad de Murcia. 